\title{
Advanced microstructural characterization of four East Antarctic firn/ice cores
}

\author{
N.E. SPAULDING, ${ }^{1}$ D.A. MEESE, ${ }^{1,2}$ I. BAKER ${ }^{2}$ \\ ${ }^{1}$ Climate Change Institute, University of Maine, 303 Bryand Global Sciences Center, Orono, Maine 04469-5790, USA \\ E-mail: nicole.spaulding@maine.edu \\ ${ }^{2}$ Thayer School of Engineering, Dartmouth College, Hanover, New Hampshire 03755-8000, USA
}

\begin{abstract}
The microstructures and microchemistry of four US International Trans-Antarctic Scientific Expedition ice cores were examined, at three depths $(30,60,90 \mathrm{~m})$ each, using scanning electron microscopy, including electron backscattered patterns and energy-dispersive spectroscopy (EDS), in order to assess the relationship between chemical and physical properties. The physical characteristics (grain size, porosity, density, internal surface volume, and crystallographic orientation) at the four sites were inhomogeneous, as expected on the basis of differences in the moisture content of deposited snow and the accumulation rate at their respective locations. Evidence of shallow subgrain boundary formation and trends in internal surface volume, having implications for the study of firn densification and ice-sheet modeling, were also found. Chemical characterization revealed that site-specific variations in particulate concentration and source could accurately be determined using EDS analysis. It was also found that the combination of elements predominant within the sample controls the morphology and microstructural location of the impurities.
\end{abstract}

\section{INTRODUCTION}

The chemistry within firn and ice cores, such as those collected by the International Trans-Antarctic Scientific Expedition (ITASE) (Mayewski, 1996; Mayewski and others, 2006), contains information about the soluble, insoluble and gaseous components of the atmosphere, as well as indicators of temperature, precipitation, atmospheric circulation, sea-ice extent and volcanic activity (Legrand and Mayewski, 1997). The microstructure of firn and ice cores, such as the size, morphology and orientation of grains, has also been shown to be indicative of the physical, mechanical and chemical characteristics of the ice sheet from which they were extracted (e.g. Alley and others, 1986, 1995a; Thorsteinsson and others, 1995; Alley and Woods, 1996; Cuffey and others, 2000). Temperature, ice flow and impurity content can all be inferred using these properties, so accurate physical properties measurements are important to our understanding of ice cores as proxies for climate. More recently, much attention has been given to characterizing the microstructural location and composition of impurities in ice cores. Knowledge of these characteristics will increase our understanding of grain growth, deformation, diffusion and electrical conduction, as well as the likelihood of post-depositional interactions that may affect the reliability of climate proxies (Kreutz and others, 1998). While much of this attention has focused on refining the methodology (Cullen and Baker, 2001; Barnes and others, 2002b, 2003; Baker and Cullen, 2003; Baker and others, 2005, 2007), defining and describing impurity types (Barnes and others, 2002a; Obbard and others, 2003; Barnes and Wolff, 2004) and studying crystallographic orientation (Baker and others 2005; Obbard and others 2006; Obbard and Baker, 2007), only limited work has been done to directly relate the morphology and microstructural location of impurities to the physical properties they are believed to affect (Barnes and others, 2002a; Iliescu and Baker, 2008). Scanning electron microscopy
(SEM) is used here to examine those relationships spatially and temporally in a suite of samples collected by the US ITASE team.

\section{METHODS}

\section{Sample collection, storage and preparation}

Eight firn and ice cores were collected during the 2006 and 2007 US ITASE traverses (Fig. 1) using the methodology described by Steig and others (2005). Four of the eight cores (06-1, 06-2, 06-3 and 07-4) were drilled to $\sim 100 \mathrm{~m}$; the other four were drilled to $\sim 40-50 \mathrm{~m}$ depth and were excluded from this study. Approximately 0.75 in $(19 \mathrm{~mm})$ thick vertical sections were cut from the selected 3 in $(\sim 76 \mathrm{~mm})$ cores. These sections were sealed in plastic and maintained in $\mathrm{a}-20^{\circ} \mathrm{C}$ freezer. On the day of analysis, horizontal subsamples (the surface analyzed is perpendicular to the core axis) were cut from these sections, and the face to be analyzed was shaved with a razor blade at $-20^{\circ} \mathrm{C}$ under a High Efficiency Particle Air (HEPA)-filtered laminar flow hood following standard clean-room practices. The final specimens were flat, smooth, free of scratches and had maximum dimensions of $0.5 \mathrm{~cm} \times 1 \mathrm{~cm} \times 3 \mathrm{~cm}$ (Cullen and Baker, 2001). Horizontal sections were taken every $10 \mathrm{~m}$ from all four cores (Table 1). Specimens were placed in a spring-loaded copper sample holder, covered with a plastic cap to prevent contamination and the formation of frost on the surface and transported to the microscopy laboratory in a liquid nitrogen atmosphere.

\section{Analytical techniques}

Scanning electron microscopy

Samples were maintained at $-110 \pm 5^{\circ} \mathrm{C}$ in the vacuum chamber of an FEI XL30 field emission gun SEM during data collection. The SEM was operated at $15 \mathrm{kV}$ with a beam current of $0.15 \mathrm{nA}$ and a spot size of $3 \mu \mathrm{m}$. During the collection of electron backscatter diffraction patterns 


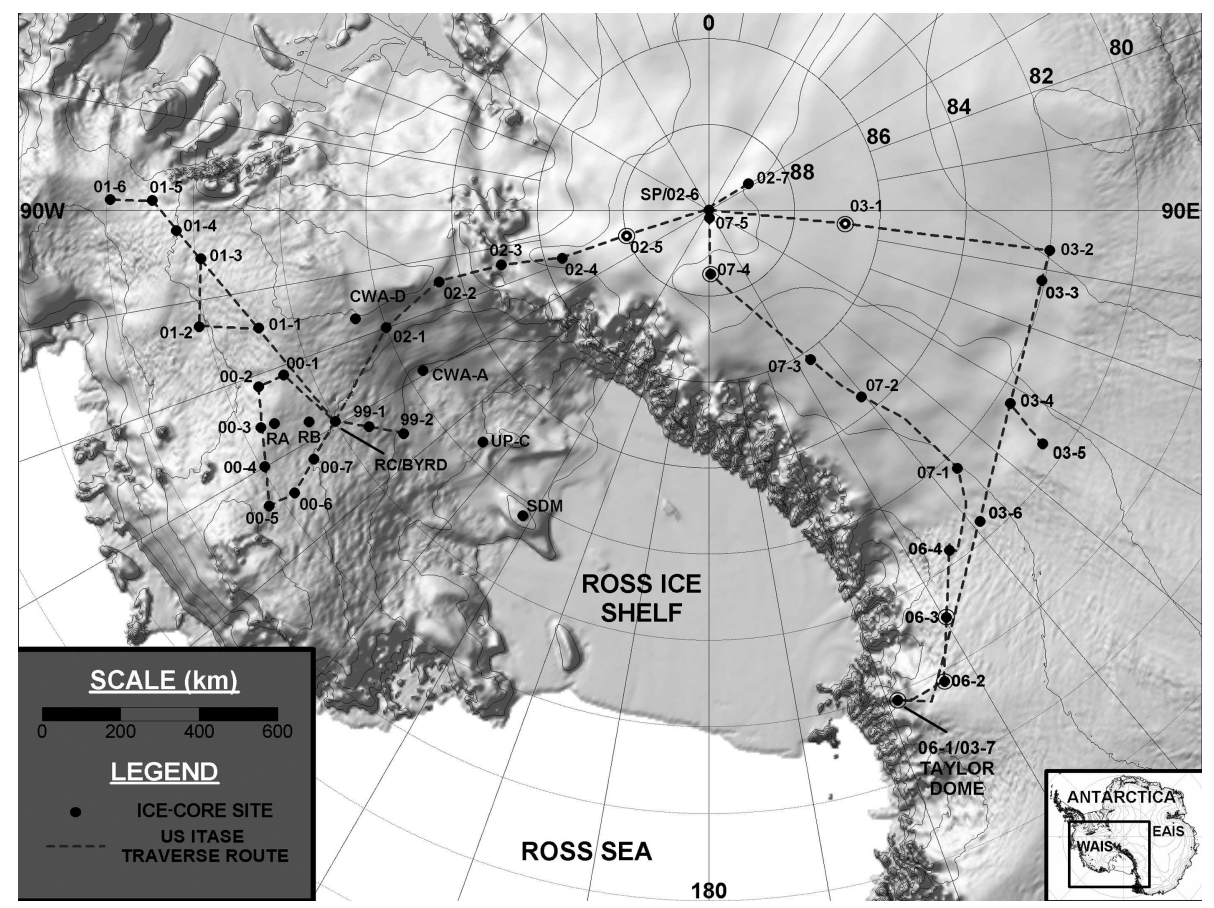

Fig. 1. Map of core locations. 06-1, 06-2, 06-3 and 07-4 (black circle with ring) are analyzed in this study. 02-5 and 03-1 (black circle with white dot and ring) are used for comparison of EDS and IC-PMS data (created by D. Dixon using RADARSAT-1 Anatarctic Mapping Project digital elevation model (RAMP DEM); H. Liu and others, nsidc.org/data/nsidc-0082.html).

(EBSPs) the spot size was increased to $5 \mu \mathrm{m}$ (Baker and others, 2007). For each sample a series of slightly overlapping SEM images was collected. These images were digitally stitched together to form a mosaic of the horizontal surface of each sample. These mosaics were used to calculate grain size and porosity. Grain sizes were determined by tracing grain boundaries on SEM images using the drawing tool in Image-Pro Plus $5.0^{\mathcal{C}}$ and then utilizing a pixel counter to determine area (Spaulding and others, 2010). Porosity was calculated as percent areal porosity by dividing the area of pores by the area of the field of view. The repeatability of porosity measurements $( \pm 1.2 \%)$ was determined by repeating the porosity determination of ten samples from different depths.

A light-element $\mathrm{Si}(\mathrm{Li})$ detector coupled to the SEM was used to collect energy-dispersive X-ray spectra (EDS) for identification of the elements present in the observed impurities. The 'concentration' is reported as the number of X-ray counts detected. The counts cannot be directly converted into a 'microgram per liter' type concentration for a number of reasons. Most of the impurities found in firn and ice are light elements, which produce a small number of low-energy photons that are readily absorbed by the surrounding ice. The decreased production and low energy of the photons result in a low signal-to-noise ratio, which reduces the accuracy of the EDS system. Additionally, the strength of the X-ray current is dependent upon both the size of the impurity analyzed (larger impurities offer a larger interaction volume) and the concentration of chemicals in the impurity. For these reasons, EDS analysis of impurities is considered qualitative, rather than quantitative (Goldstein and others, 1992). EDS were collected from triple junctions, filaments, grain boundary ridges, grain boundary grooves and crystal facets from at least three distinct locations per sample. Background spectra were also taken from areas presumed to be pure ice for purposes of comparison.
EBSPs were obtained for each core at $\sim 90 \mathrm{~m}$ depth using an HKL, Inc. Channel 5 Orientation Imaging System (Day and others, 2004). Due to the size restrictions of the sample holder and the grain size at these depths, more than one ice sample was required to obtain enough patterns to produce statistically significant data. Additionally, because EBSPs in ice can be difficult to index, not all patterns collected are usable. In this study, at least 60 patterns from each sample were of a high enough quality to index. EBSPs, such as those shown in Figure 2, were indexed to produce pole figures for both the a-axes and $c$-axes using the HKL (CHANNEL 5) pole-figure and inverse pole-figure software package Mambo ${ }^{(}$. Imaging was performed using a forward-scatter electron detector, and EBSPs were obtained by stopping the beam at a point of interest. Patterns were produced by backscattered electrons collected on a phosphor screen and

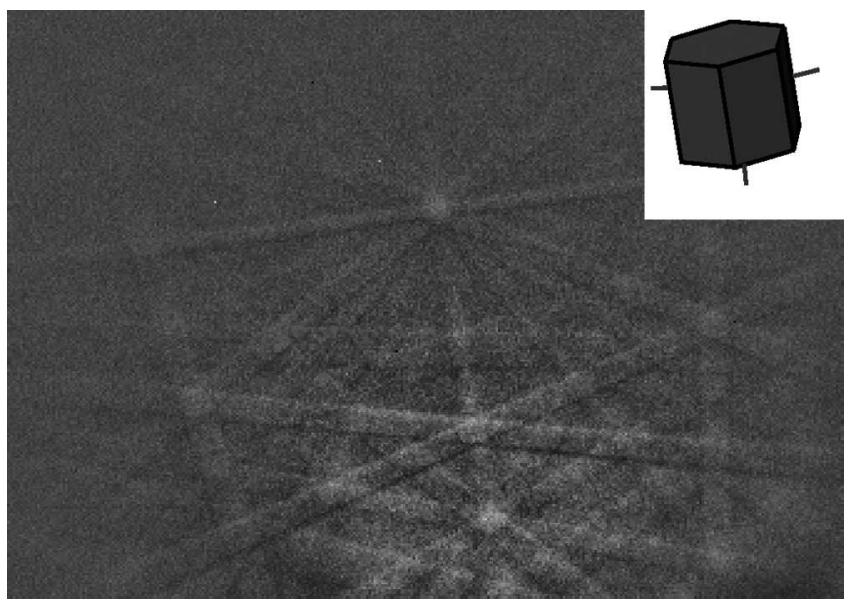

Fig. 2. Electron backscatter diffraction pattern from ice with its corresponding crystal orientation. 
Table 1. Physical properties data for the firn cores used in this study. Grain size and density increase with depth, while porosity and internal surface volume $\left(S_{\mathrm{V}}\right)$ decrease with depth

\begin{tabular}{|c|c|c|c|c|c|c|}
\hline Site & Identifier & $\begin{array}{l}\text { Depth } \\
\text { m }\end{array}$ & $\begin{array}{l}\text { Density } \\
\mathrm{g} \mathrm{cm}^{-3}\end{array}$ & $\begin{array}{c}\text { Grain size } \\
\mathrm{mm}^{2}\end{array}$ & $\begin{array}{c}\text { Porosity } \\
\%\end{array}$ & $\begin{array}{c}S_{\mathrm{V}} \\
\mathrm{mm}^{-1}\end{array}$ \\
\hline 2006-1 & 11 & 10.45 & 0.50 & 0.35 & 60 & 2.07 \\
\hline 2006-1 & 22 & 20.91 & 0.61 & 0.42 & 43 & 2.23 \\
\hline 2006-1 & 33 & 30.9 & 0.66 & 0.51 & 67 & 1.88 \\
\hline 2006-1 & 43 & 41.53 & 0.69 & 0.61 & 53 & 2.25 \\
\hline 2006-1 & 53 & 50.28 & 0.76 & 0.88 & 27 & 1.53 \\
\hline 2006-1 & 63 & 60.23 & 0.79 & 0.81 & 21 & 1.35 \\
\hline 2006-1 & 74 & 70.54 & 0.87 & 0.99 & 13 & 1.26 \\
\hline 2006-1 & 85 & 80.28 & 0.88 & 0.98 & 10 & 0.75 \\
\hline 2006-1 & 97 & 90.17 & 0.90 & 1.39 & 8 & 0.69 \\
\hline $2006-2$ & 10 & 10.37 & 0.44 & 0.36 & 64 & 1.85 \\
\hline $2006-2$ & 20 & 20.22 & 0.60 & 0.47 & 53 & 2.17 \\
\hline $2006-2$ & 26 & 25.87 & 0.60 & 0.40 & 42 & 2.38 \\
\hline $2006-2$ & 36 & 35.1 & 0.66 & 0.45 & 33 & 2.01 \\
\hline $2006-2$ & 51 & 50.38 & 0.73 & 0.63 & 31 & 2.19 \\
\hline 2006-2 & 61 & 60.1 & 0.76 & 0.70 & 27 & 1.72 \\
\hline 2006-2 & 77 & 75.24 & 0.74 & 0.95 & 21 & 1.50 \\
\hline 2006-2 & 83 & 80.37 & 0.76 & 1.20 & 18 & 1.35 \\
\hline 2006-2 & 96 & 90.62 & 0.80 & 1.19 & 12 & 0.86 \\
\hline $2006-2$ & 102 & 95.29 & 0.82 & 1.72 & 11 & 0.71 \\
\hline 2006-3 & 10 & 10.05 & 0.52 & 0.25 & 66 & 2.47 \\
\hline 2006-3 & 21 & 20.91 & 0.58 & 0.35 & 45 & 2.38 \\
\hline 2006-3 & 30 & 30 & 0.64 & 0.61 & 73 & 1.99 \\
\hline $2006-3$ & 40 & 41.13 & 0.70 & 0.59 & 36 & 2.32 \\
\hline 2006-3 & 50 & 50.25 & 0.73 & 0.61 & 27 & 1.98 \\
\hline 2006-3 & 60 & 60.39 & 0.78 & 0.57 & 36 & 2.48 \\
\hline 2006-3 & 70 & 70.01 & 0.78 & 0.84 & 24 & 1.53 \\
\hline 2006-3 & 81 & 80.11 & 0.81 & 0.74 & 15 & 1.32 \\
\hline 2006-3 & 92 & 90.04 & 0.84 & 0.86 & 18 & 1.33 \\
\hline 2006-3 & 104 & 100.47 & 0.86 & - & 8 & 0.32 \\
\hline 2007-4 & 10 & 11.45 & 0.51 & 0.16 & 63 & 2.88 \\
\hline $2007-4$ & 19 & 20.3 & 0.55 & 0.26 & 59 & 2.47 \\
\hline $2007-4$ & 29 & 30.4 & 0.59 & 0.26 & 69 & 3.62 \\
\hline $2007-4$ & 40 & 40.03 & 0.66 & 0.29 & 21 & 2.08 \\
\hline 2007-4 & 50 & 49.31 & 0.67 & 0.57 & 28 & 1.80 \\
\hline $2007-4$ & 61 & 60.12 & 0.71 & 0.33 & 34 & 2.31 \\
\hline $2007-4$ & 71 & 70.19 & 0.73 & 0.37 & 35 & 2.09 \\
\hline 2007-4 & 82 & 80.4 & 0.75 & 0.40 & 37 & 2.48 \\
\hline $2007-4$ & 92 & 87.89 & 0.78 & 0.58 & 26 & 1.85 \\
\hline $2007-4$ & 103 & 99.8 & 0.79 & 0.62 & 31 & 1.76 \\
\hline $2007-4$ & 110 & 106.75 & - & 0.61 & 20 & 1.26 \\
\hline
\end{tabular}

recorded using a charge-coupled device (CCD) camera. The sample was held by a copper sample holder pre-tilted to $10^{\circ}$, and the stage was tilted an additional $60^{\circ}$ to maximize backscattering yield.

\section{EXPERIMENTAL RESULTS}

\section{Stratigraphy}

Stratigraphic analysis was conducted both in the field and in the laboratory. Each section of core was placed on a light table, and the locations of coarse (summer) layers, fine (winter) layers, ice layers, wind crusts and other pertinent data were recorded at the millimeter scale.

\section{Physical properties}

Grain size

As expected, grain size in all cores showed a linear increase with depth (Fig. 3) (Stephenson, 1967; Gow, 1969), driven by the reduction in free energy associated with a decrease in grain boundary area. The four cores in this study also exhibit a decrease in grain size with distance from the coast, i.e. core 06-1 located at Taylor Dome (near the coast) has the largest grain size, whereas core 07-4 located at Titan Dome (near South Pole) has the smallest grain size. The change in grain size is attributable to the decrease in mean annual temperature on moving inland (J. Bohlander and T. Scambos, http:// nsidc.org/data/docs/agdc/thermap/documentation.html).

\section{Porosity}

Core 06-2 has the lowest average porosity, with cores 06-1 and 06-3 being approximately equivalent. However, 06-1 is less porous at all depths except 30 and $40 \mathrm{~m}$. Visual stratigraphy indicates that these samples were taken from a coarse layer, whereas those from equivalent depths in cores 06-2 and 06-3 were taken from a fine layer, indicating differences in seasonality. Samples were taken from the bottom of each core section without regard for seasonality; if 

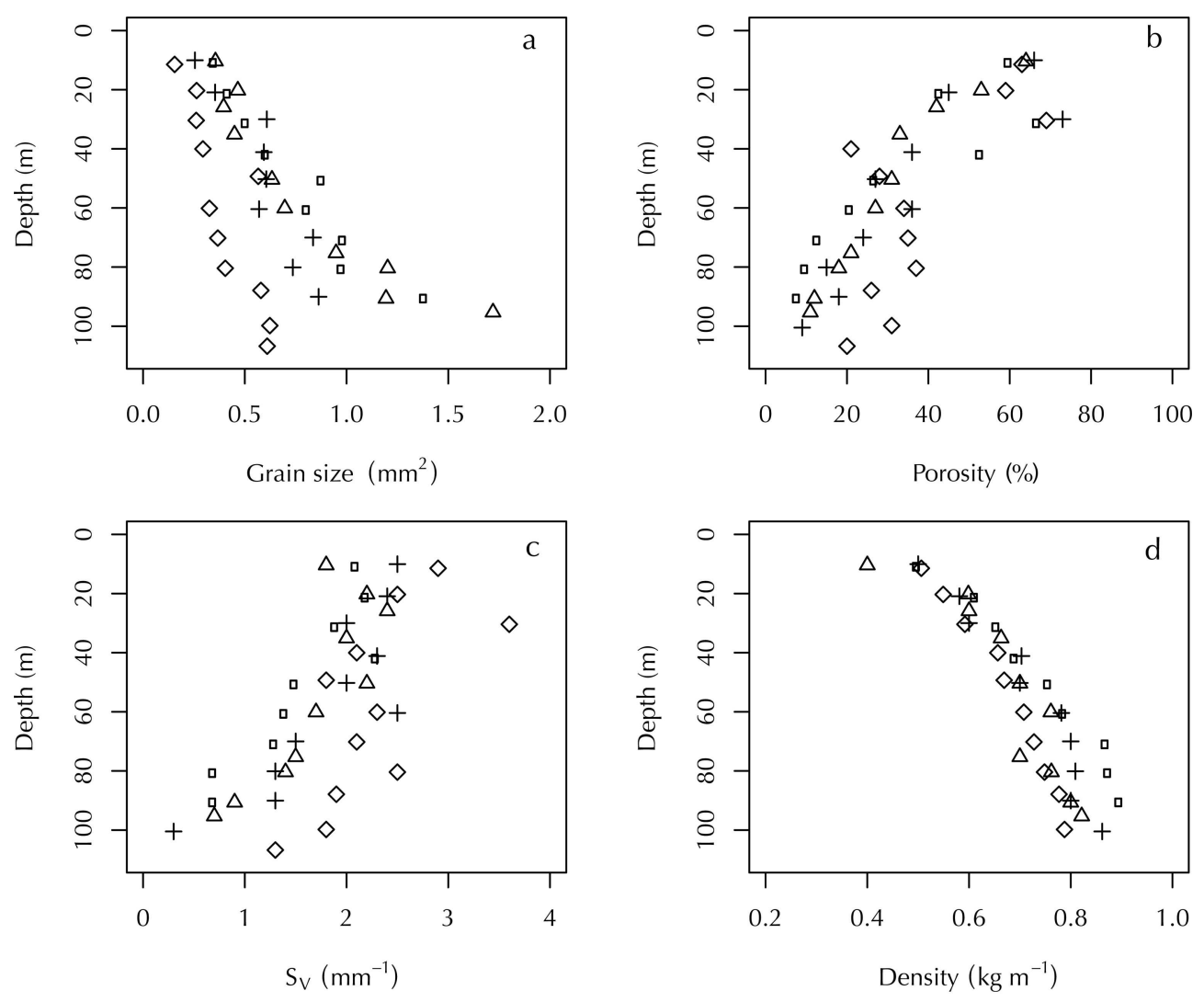

$061 \triangle 062+063 \diamond 074$

Fig. 3. Physical properties data for the four cores used in this study. Grain size (a) and density (d) increase with increasing depth, while porosity (b) and internal surface volume $S_{\mathrm{V}}$ (c) decrease with increasing depth. 06-1 has the highest porosity and $S_{\mathrm{V}}$ and the lowest density and grain size. 07-4 has the opposite pattern, primarily as a result of the much lower mean annual temperature at this site.

the samples from core 06-1 had been taken from a fine layer, it would likely have the lowest average porosity, in accordance with having the highest overall grain size. Core 07-4 has the highest overall porosity as determined using SEM images, although it may not be significantly different from cores 06-2 or 06-3. The porosity values measured from core 07-4 were erratic and did not exhibit the typical trend of decreasing with depth. A correlation coefficient, $r$, of 0.72 was found for core 07-4 between porosity and depth by forcing the intercept of the trend line to zero. In order for the correlation to be significant at the 95\% level, $r$ (with nine degrees of freedom) must be at least 0.735. All other cores had an $r$ for porosity versus depth of $>0.88$, which was statistically significant. Ground-penetrating radar (GPR) profiles indicate that coarse-grained hoar layers are thicker and more frequent at site 07-4 than at any of the 06 sites (personal communication from S.A. Arcone, 2008). Visual stratigraphy shows a similar trend, a greater number of thick coarse-grained hoar layers than of thinner fine-grained layers. At all other sites, the number of coarse and fine layers is similar and the fine layers tend to be thicker. The increased chance of sampling an irregular hoar layer likely contributes to the erratic porosity measurements.

\section{Internal surface volume per area}

The internal surface volume per unit area was calculated as

$$
S_{\mathrm{V}}=4 L_{\mathrm{A}}
$$

where $L_{\mathrm{A}}$ is the length of the internal surface lines per unit area as determined by dividing the length of the projected surface around pores by the bounding area of those pores. $S_{\mathrm{V}}$ is a measure of the complexity or tortuosity of the pores. Core $07-4$ has the highest overall complexity, while core 06-1 has the lowest. In each core, $S_{\mathrm{V}}$ increases between 10 and $40-60 \mathrm{~m}$ and decreases between $40-60$ and $100 \mathrm{~m}$. Baker and others (2007) used samples with a depth range of 10-40 $\mathrm{m}$ in US ITASE cores 02-SP and 02-5 and also found that $S_{V}$ increased with depth. Because $S_{V}$ depends on the length of pore outlines, Baker and others (2007) hypothesized that the increase to $40-60 \mathrm{~m}$ was a result of increasing convolution of pore outlines as the grains were flattened with increasing overburden. The $S_{\mathrm{V}}$ values in this study and in Baker and others (2007) can be explained by assuming that $S_{V}$ is initially low when each grain is an island and then increases as the grains merge and their outlines become more complex to $40-60 \mathrm{~m}$. Once the maximum possible number of contacts between grains has been made, the complexity of the outline no longer changes. Thus, below this depth, continued overburden pressure causes a decrease in pore size, pore outline length and consequently $S_{V}$. This explanation and the trends in $S_{V}$ agree well with established models of firn densification, which divide the process into three stages. In the first stage, individual grains or small groups of grains are distinguishable within the pores, in the intermediate stage the interconnection of pores is decreased as the contact area between grains reaches a maximum and in the final stage closed-off spherical pores are established (Anderson and Benson, 1963; Maeno and Ebinuma, 1983; 


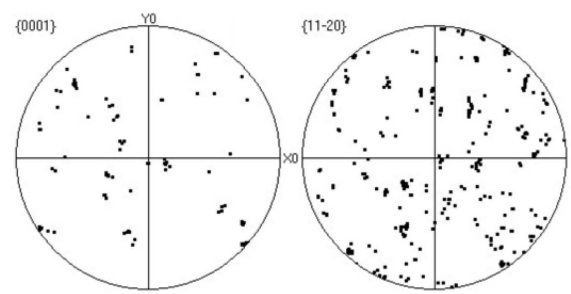

06-1-97 $\mathrm{N}=102$

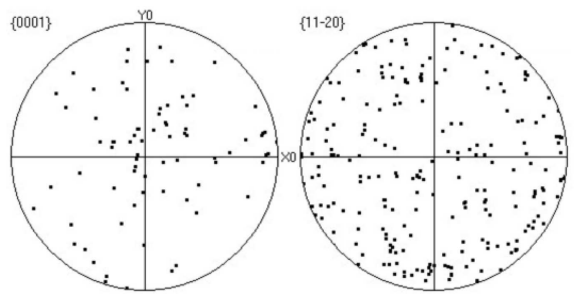

06-3-92 $\quad \mathrm{N}=77$

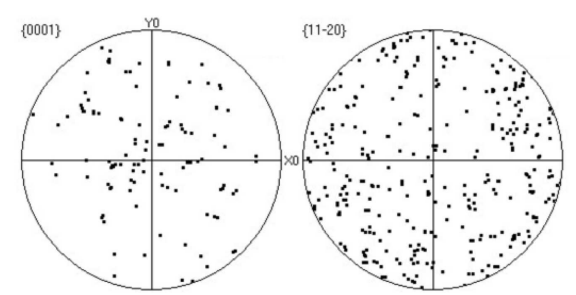

06-2-96 $\mathrm{N}=108$

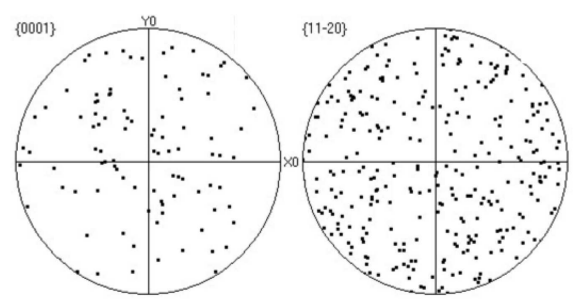

07-4-92 N=100

Fig. 4. $\{0001\}$ and $\{1120\}$ pole figures for samples from $\sim 90 \mathrm{~m}$ depth. Statistically significant preferred orientations are found in all four samples. $N$ indicates the number of grains examined in each core.

Alley, 1987; Ebinuma and Maeno, 1987; Wilkinson, 1988; Arnaud and others 1998, 2000; Freitag and others 2004).

\section{Density}

Bulk density $(\rho)$ measurements were performed for each core section immediately after retrieval in the field. These measurements revealed that in addition to having the lowest porosity value and the highest degree of anisotropy of pore space, core 06-1 had the highest rate of densification of the four cores $\left(0.0056 \mathrm{~kg} \mathrm{~m}^{-4}\right.$, i.e. $\mathrm{kg} \mathrm{m}^{-3}$ per meter of ice in each core section). Core 07-4 had the lowest rate of densification, although the difference in the rates of densification between $06-2\left(0.0037 \mathrm{~kg} \mathrm{~m}^{-4}\right), 06-3\left(0.0039 \mathrm{~kg} \mathrm{~m}^{-4}\right)$ and $07-4\left(0.0036 \mathrm{~kg} \mathrm{~m}^{-4}\right)$ were very small and likely not statistically significant.

\section{Crystallographic orientation}

The $\{0001\}$ and $\{1120\}$ pole figures produced for each core at $\sim 90 \mathrm{~m}$ are shown in Figure 4 . The random distribution of the points in the scatter plots suggests that the grains from all four cores do not have a strongly preferred orientation. The strength of the $c$-axis fabric was tested using the method of Kamb (1959), in which a coefficient $f$ is calculated by dividing the number of $c$-axes, $N_{A}$, in an area of the projection, $A$, by the standard deviation, $\sigma$, of the number of axes expected from a random distribution. Both $A$ and $\sigma$ are

Table 2. Determination of the strength of the $c$-axis fabric using Kamb (1959). Variables are outlined in the text

\begin{tabular}{lrrrr}
\hline Sample & $N_{\text {SAMP }}$ & $\sigma$ & $N_{\text {A }}$ & $f$ \\
\hline 06-1-97 & 102 & 2.6 & 20 & 8 \\
06-1-97b & 76 & 2.5 & 17 & 7 \\
06-2-96 & 108 & 2.7 & 25 & 9 \\
$06-3-92$ & 77 & 2.5 & 25 & 10 \\
$07-4-92$ & 100 & 2.6 & 19 & 7 \\
\hline
\end{tabular}

determined by a statistical relationship from the number of data points evaluated, $N_{\text {SAMP, }}$ such that when $N_{\text {SAMP }}$ increases, $A$ decreases and $\sigma$ increases. A value of $f<3$ is expected when there is no preferred orientation. Statistically significant preferred orientations indicate that the density of points within $A$ could not have resulted from the random sampling of a population with no preferred orientation and are described by $f \geq 6$. Strongly preferred orientations are described by much higher numbers: for example, Hooke and Hudleston (1980) report a strength of 31 for a singlemaximum fabric from $156 \mathrm{~m}$ depth in Barnes Ice Cap, Canada. All the fabrics analyzed in this study were shown to be statistically significant (Table 2).

\section{Chemical properties}

\section{Elemental chemistry}

In order to determine whether the elemental chemistry or the distribution of impurities changed with depth, samples from approximately 30, 60 and $90 \mathrm{~m}$ in each core were analyzed using EDS. Figure 5 shows the average intensity in counts $\mathrm{s}^{-1}$ of the eight most common elements at each depth in each core and allows inter-site comparison. Although depth was used to identify each sample, the seasonality and age of the stratigraphic layer is more important to the comparison of chemistry than depth alone. Figure 6 shows the average frequency with which each element occurred in either winter or summer, as determined by visual stratigraphy, and allows a comparison of seasonal influences. It may be assumed that an element occurring with greater frequency contributes more significantly to the aerosol/dust loading at the time of deposition.

\section{ANALYTICAL RESULTS Elemental factor analysis}

Factor analysis, a type of multivariate statistical analysis (Fitch, 2007), was used to examine the elemental associations in each of the four cores for which chemical data were collected. Factor analysis attempts to explain the correlation 

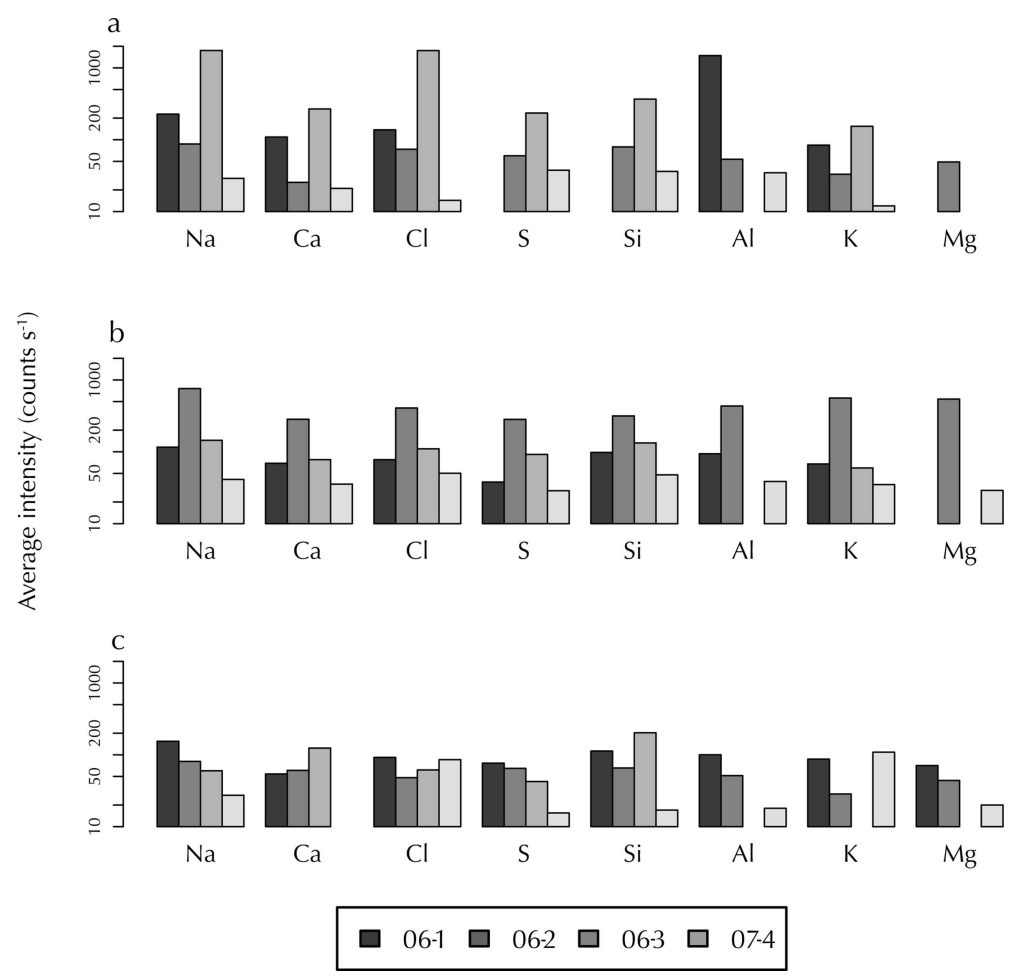

Fig. 5. The average intensity of the eight most common elements at (a) $30 \mathrm{~m}$, (b) $60 \mathrm{~m}$ and (c) $90 \mathrm{~m}$ depth. Note that in most cases intensity (concentration) is greatest at 06-1 and lowest at 07-4.

between a large number of variables in terms of a small number of underlying factors (Mardia and others, 1979). Those factors are determined through the extraction of eigenvalues from the data correlation matrix. Factors with eigenvalues greater than 1 represent statistically significant groups of variables (Kaiser, 1960) and are retained. The factor with the highest eigenvalue, $F 1$, explains the highest percent of the variability in the data. The variables assigned to each factor are determined by the significance of their correlations with that factor and are expressed as factor loading. More easily interpreted results are produced when the initial solution is rotated. In this study, Varimax orthogonal rotation (Davis, 2002) is employed. Factor loadings greater than 0.7 indicate variables within a factor that are significantly correlated. In Tables 3 and 4, these values are italicized. Factor loadings less than 0.4 are not considered significant and are excluded from Tables 3 and 4 (MilHomens and others, 2009). A high degree of association between variables is indicated by factor loadings of similar magnitude. Inverse relationships between variables are indicated by factor loadings opposite in sign.

Non-elemental characteristics, such as depth, grain size, porosity and impurity structure or location are also included in the factor analysis (Table 3). Impurity features are as follows: BWS: bright white spots; GB: grain boundaries; TJ: triple junctions (the intersection of three grains); ICE: background (parts of the sample that appear gray in SEM images); INC: large inclusions (insoluble impurities); TAN: filament tufts; and FIL: filaments. An example of each impurity structure or location is shown in Figure 7. Representative EDS spectra for several impurity types are shown in Figure 8. Factor analysis was meant to answer not only questions about the elemental associations, but also questions about the relationship between the elements and the non-elemental characteristics: for example, is the morphology or microstructural location of the impurities indicative of a particular chemical composition, provenance or transport mechanism?

\section{DISCUSSION Glaciology}

The physical and chemical properties characterized above can be used to infer the flow history of the ice sheet in the immediate vicinity of each of the cores. As illustrated by the

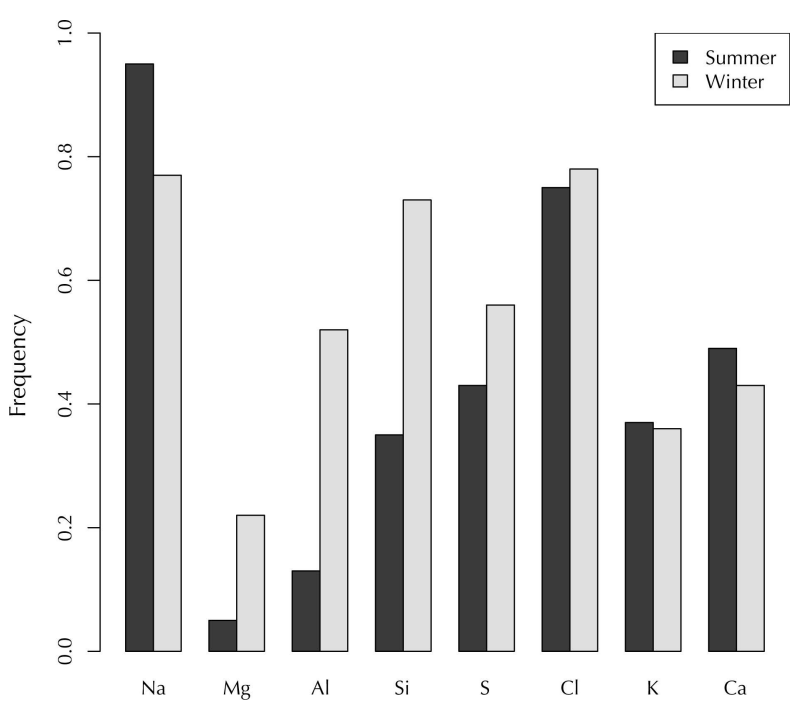

Fig. 6. Frequency of occurrence of the eight most common elements in winter and summer layers as determined by visual stratigraphy. Frequency is calculated by dividing the number of times that element is seen by the number of spectra from that season containing chemistry beyond background levels. 
Table 3. Results from the factor analysis in each core. Factor loadings greater than 0.7 are italicized

\begin{tabular}{|c|c|c|c|c|c|c|c|}
\hline & $F 1$ & $F 2$ & F3 & & F1 & $F 2$ & F3 \\
\hline \multicolumn{4}{|l|}{ A. Core 06-1 } & \multicolumn{4}{|l|}{ B. Core 06-2 } \\
\hline $\mathrm{Al}$ & 0.94 & - & - & $\mathrm{Al}$ & 0.62 & -0.53 & 0.58 \\
\hline $\mathrm{Ca}$ & 0.98 & - & - & $\mathrm{Ca}$ & 0.98 & - & - \\
\hline $\mathrm{Cl}$ & - & - & 0.66 & $\mathrm{Cl}$ & 0.91 & - & - \\
\hline Depth & -0.97 & - & - & Depth & - & 0.94 & - \\
\hline Grain size & -0.97 & - & - & Grain size & - & 0.94 & - \\
\hline BWS & & -0.88 & - & BWS & - & - & 0.90 \\
\hline GB & -0.80 & 0.60 & - & GB & -0.50 & - & -0.76 \\
\hline TJ & -0.93 & - & - & TJ & - & 0.86 & \\
\hline ICE & - & 0.94 & - & ICE & - & 0.43 & - \\
\hline INC & - & 0.90 & - & INC & - & - & - \\
\hline TAN & 0.52 & 0.82 & - & TAN & - & - & - \\
\hline FIL & - & 0.96 & - & FIL & 0.95 & - & - \\
\hline K & - & 0.48 & 0.79 & K & 0.99 & - & - \\
\hline Mg & 0.87 & - & - & Mg & 0.97 & - & - \\
\hline $\mathrm{Na}$ & 0.79 & - & - & $\mathrm{Na}$ & 0.67 & -0.71 & - \\
\hline$P$ & - & - & & $P$ & - & - & - \\
\hline Porosity & 0.81 & - & -0.51 & Porosity & - & -0.94 & - \\
\hline$S$ & - & - & 1.00 & $\mathrm{~S}$ & 0.90 & - & - \\
\hline $\mathrm{Si}$ & 0.96 & - & - & $\mathrm{Si}$ & 0.63 & -0.77 & - \\
\hline \multirow[t]{2}{*}{$\%$ of variance } & 50.7 & 28.2 & 15.1 & $\%$ of variance & 45.17 & 33.30 & 12.60 \\
\hline & $F 1$ & $F 2$ & F3 & & $F 1$ & $F 2$ & F3 \\
\hline
\end{tabular}

\section{Core 06-3}

\section{$\mathrm{Al}$}

$\mathrm{Ca}$

$\mathrm{Cl}$

Grain size

BWS

GB

TJ

ICE

INC

TAN

FIL

K

$\mathrm{Mg}$

$\mathrm{Na}$

$\mathrm{P}$

Porosity

$\mathrm{S}$

Si

$\%$ of variance

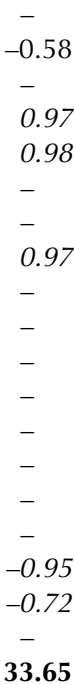

-

0.98

$-$

0.97

$-$

$-$

$-$

$-$

$-$

0.95

0.72

33.65

$\begin{array}{ll} & \\ - & - \\ - & 0.65 \\ 0.96 & - \\ - & - \\ - & - \\ - & - \\ - & -0.68 \\ - & - \\ - & - \\ - & -0.61 \\ - & - \\ 0.99 & - \\ - & 0.83 \\ - & - \\ 0.97 & - \\ - & - \\ - & - \\ 0.67 & - \\ 0.86 & - \\ \mathbf{2 9 . 6 7} & \mathbf{1 4 . 6 7} \\ & \end{array}$

\section{Core 06-4}

$\begin{array}{lc}\text { Al } & -0.72 \\ \text { Ca } & 0.71 \\ \text { Cl } & 0.72 \\ \text { Depth } & 0.93 \\ \text { Grain size } & 0.94 \\ \text { BWS } & - \\ \text { GB } & - \\ \text { TJ } & - \\ \text { ICE } & - \\ \text { INC } & - \\ \text { TAN } & -0.86 \\ \text { FIL } & 0.87 \\ \text { K } & 0.76 \\ \text { Mg } & - \\ \text { Na } & - \\ \text { P } & 0.54 \\ \text { Porosity } & -0.91 \\ \text { S } & -0.56 \\ \text { Si } & -0.86 \\ \text { \% of variance } & \mathbf{4 5 . 5 7}\end{array}$

$\begin{array}{lc}- & - \\ - & -0.58 \\ 0.49 & -0.43 \\ - & - \\ - & - \\ - & 0.83 \\ -0.50 & -0.63 \\ - & - \\ - & - \\ 0.78 & - \\ - & - \\ - & - \\ 0.59 & - \\ 0.88 & - \\ - & -0.77 \\ - & - \\ - & - \\ - & - \\ - & - \\ \mathbf{1 6 . 7 2} & \mathbf{1 6 . 5 8}\end{array}$

pole figures, with the exception of sample 06-1-97, the samples from $\sim 90 \mathrm{~m}$ appear to have similar deformation history. Although the $f$ value of $06-1-97$ is similar to that of the other samples, the appearance of the pole figure shows it is different. The clustering of poles seen in 06-1-97 has several possible explanations. Polygonization would result in grains with low-angle grain boundaries and cause the appearance of clustering; however, it is also possible that grains were analyzed in duplicate. To ensure that duplicate grains were not included, points of analysis with a misorientation less than $3.0^{\circ}$ (the angular resolution of the SEM at the magnifications used) were considered to have been conducted on the same grain, and one grain in the pair was eliminated from the results. $A, \sigma$ and $f$ were recalculated using the new $N_{\text {SAMP }}$ of 76 . A statistically significant preferred $c$-axis orientation was still found in 06-1, although the magnitude of $f$ was less than that calculated previously (Table 2; 06-1-97b) and some clustering was still evident.

Having eliminated duplicate analyses of single grains, the clustering indicates low-angle grain boundaries. The presence of so many low-angle grain boundaries in a sample with so little accumulated strain history is unexpected. If the sample were from a deeper section of the ice core, their presence could be explained by polygonization (heterogeneous deformation resulting in the organization of dislocations into sub-boundaries) and rotation recrystallization (boundaries become larger and the subgrains split into two distinct grains) (Alley, 1992; Alley and others, 1995b; Durand and others, 2008). Rotation recrystallization does not typically occur in the uppermost sections of ice sheets 



Fig. 7. The seven impurity features analyzed are shown. Magnification of black bounding boxes in the left images is shown in the images to the right.

(Alley, 1992); however, several recent studies have found evidence suggesting otherwise. For example, Durand and others (2008) found an over-representation of low-angle grain boundaries in textures analyzed from depths as shallow as $115 \mathrm{~m}$ in the NorthGRIP (North Greenland Icecore Project) core, indicating the occurrence of rotation crystallization. Further, Thorsteinsson's (2002) model results show that inhomogeneous strain can lead to dynamic recrystallization even at low bulk strain. Hamann and others (2004) found that crystalline deformation is highly inhomogeneous, even close to the ice-sheet surface, and showed subgrain boundaries in samples from only $104 \mathrm{~m}$ depth. Finally, Kipfstuhl and others (2006) showed that the shade of gray in their images of ice thin sections under crossed polarizers changed not only across wide dark lines (grain boundaries) but also across weak complex lines (subgrain boundaries), indicative of early deformation. In the study presented here, evidence of subgrain boundaries, such as those described by Kipfstuhl and others (2006), was found in samples as shallow as $40 \mathrm{~m}$ (Fig. 9). Also suggestive of deformation in the upper part of ice sheets is the discontinuous increase in grain size between 40 and $70 \mathrm{~m}$ in cores 06-1, 06-2 and 06-3, which may indicate an increase in the number of low-angle grain boundaries below $40 \mathrm{~m}$, as low-angle grain boundaries have less energy and therefore sublimate less rapidly, making the boundaries difficult or impossible to see. It is therefore possible that the clustering seen in the $\sim 90 \mathrm{~m}$ sample from core $06-1$ is indicative of shallow subgrain formation. These findings also suggest that shallow ice-sheet metamorphism does occur and should be given consideration in ice-flow modeling.

\section{Chemistry}

The primary sources of impurities in Antarctic ice sheets are sea-salt aerosols, dust particulates and volcanic and biogenic emissions (Legrand and Mayewski, 1997). Chemical characterization of ice cores is typically done using ion chromatography (IC) or inductively coupled plasma mass spectrometry (IC-PMS). IC is used to measure the dissolved chemistry of major ions $\left(\mathrm{Na}^{+}, \mathrm{K}^{+}, \mathrm{Mg}^{2+}, \mathrm{Ca}^{2+}, \mathrm{CH}_{3} \mathrm{SO}_{3}{ }^{-}, \mathrm{Cl}^{-}\right.$, 


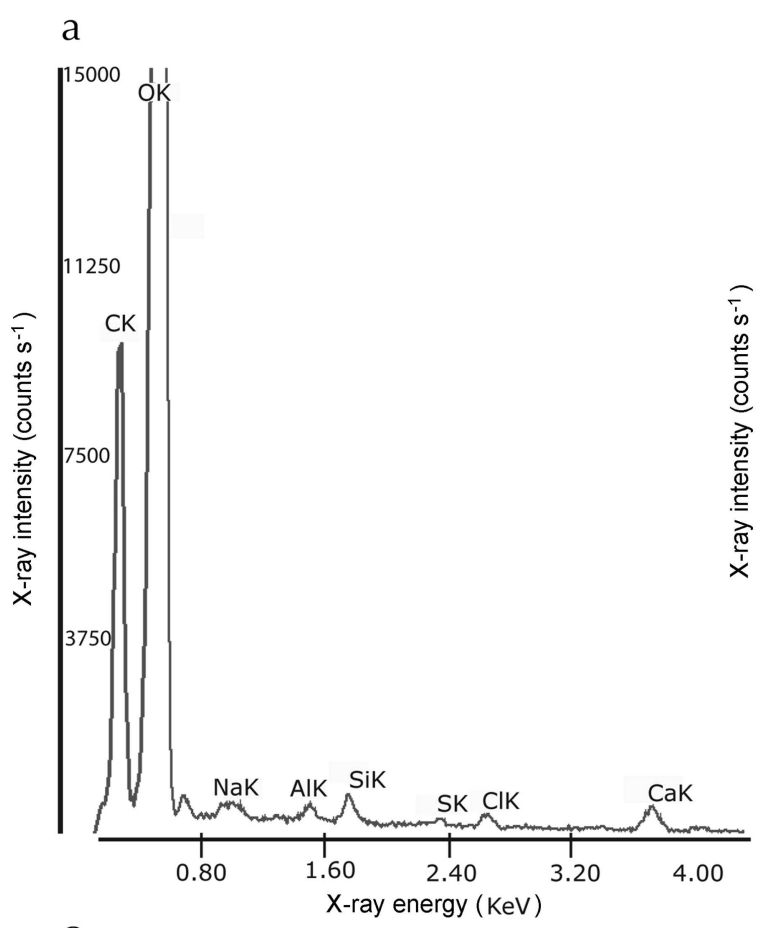

C

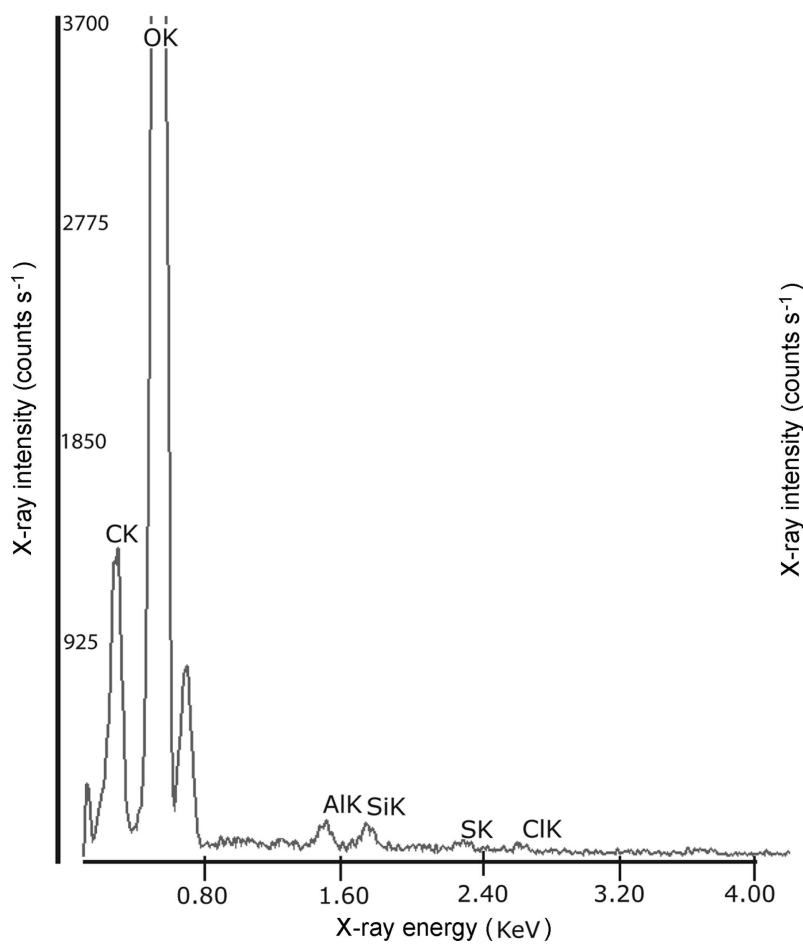

b

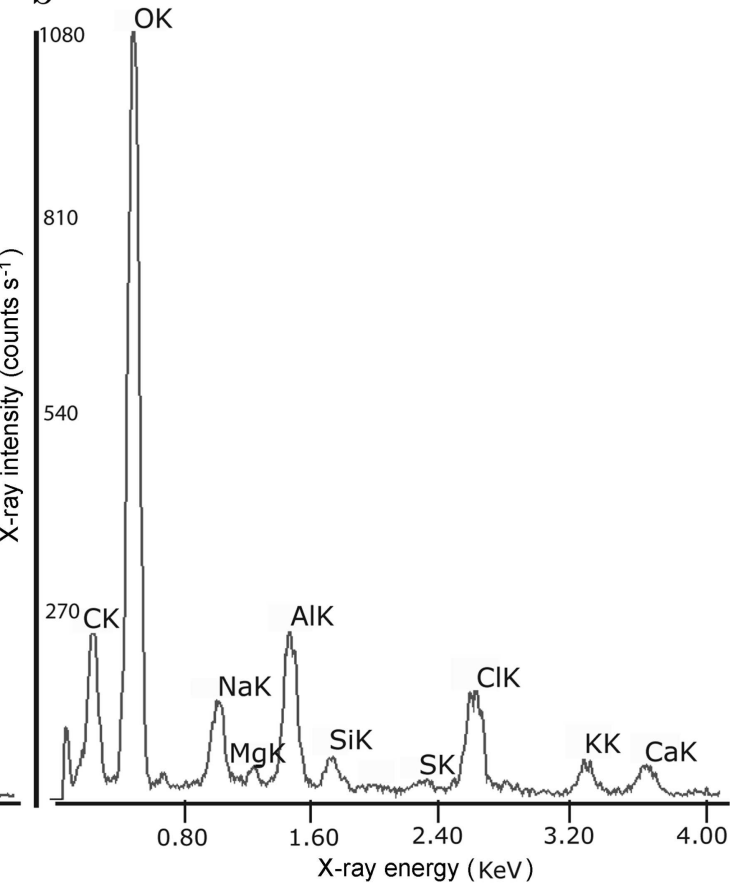

d

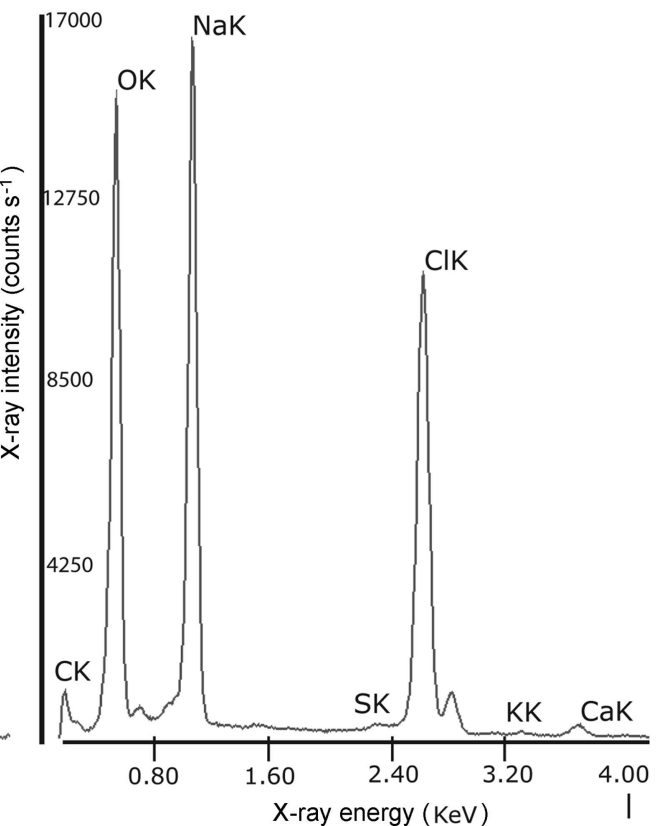

Fig. 8. EDS spectra for common impurity features. (a) Bright white spot (BWS). (b) Inclusion (INC). (c) Filament tuft/tangle (TAN). (d) Filament (FIL).

$\mathrm{NO}_{3}{ }^{-}$and $\mathrm{SO}_{4}{ }^{2-}$ ). IC-PMS is used to measure the trace element chemistry (e.g. ${ }^{27} \mathrm{Al},{ }^{44} \mathrm{Ca},{ }^{56} \mathrm{Fe},{ }^{63} \mathrm{Cu}$, etc.), which requires the acidification of meltwater samples in order to dissolve particulates. IC-PMS therefore measures total bulk chemistry. In this subsection, trends in chemistry derived using EDS are compared with trends in chemistry derived using these traditional methods.

\section{Trends in concentration}

A generally decreasing trend in the concentrations of all of the eight most common elements (Fig. 5) between core 06-1 at Taylor Dome $(\sim 150 \mathrm{~km}$ from the coast) and core $07-4$ at South Pole $(\sim 1300 \mathrm{~km}$ from the coast) was found in this study. Bertler and others (2005) reported similar trends in snow surface chemistry, as did Thompson and MosleyThompson (1982) who found that annual particulate loading decreases as a function of the mean distance from open water, as does the accumulation rate (Bromwich, 1988; Zwally and Giovinetto, 1997). In this study, the K counts from 07-4-92 were the only exception to the trend exhibited by the EDS samples. The increased concentration of $\mathrm{K}$ may be a by-product of the random sampling of impurities as 
only one impurity analyzed in 06-1-97 contained $\mathrm{K}$ and the majority of the $\mathrm{K}$ counts in 07-4-92 were lower than those in 06-1-97. Differences in the seasonality of the samples analyzed at $90 \mathrm{~m}$ or the size of the one particle containing $\mathrm{K}$ may also account for this difference.

The general trend of decreasing concentration with distance from the coastline was observed in samples from cores 06-1 and 07-4; however, it was not seen in cores 06-2 and 06-3. There is very little difference in distance to the coast between these two sites, so concentration differences between them should be negligible or nonexistent. If any changes in concentration do exist, capturing those changes within sample sites nearly equidistant from the coast likely requires more points of EDS analysis. However, this study has shown that EDS analysis is capable of accurately characterizing differences in impurity loading between the Antarctic coast and the interior and has the potential to do so on a more geographically limited scale if higher sampling density is employed.

\section{Trends in provenance}

Factor analysis in core 06-1 (Taylor Dome) found Ca loaded on $F 1$ at the same magnitude as other continental dust elements (Al, Si). Na loaded on the same factor, but was dissimilar in magnitude, indicating a weaker association with the dust elements (Table 3A). When factor analysis containing only the elemental variables was performed, Ca and $\mathrm{Na}$ separated onto distinct factors representing the dust and sea-salt contributions, respectively. These findings are similar to trends reported using IC and IC-PMS where the majority of Ca loading at Taylor Dome is attributed to continental dust sources and $\mathrm{Na}$ is attributed primarily to sea salt (De Angelis and others, 1997; Legrand and Mayewski, 1997; Steig and others, 2000).

In core 07-4 (South Pole) $\mathrm{Ca}$ and $\mathrm{Cl}$ are strongly associated on $\mathrm{F} 1$ and weakly associated on $\mathrm{F3}$. Cl was also associated with $\mathrm{Na}$ on $\mathrm{F3}$. These relationships indicate a seasalt source for both $\mathrm{Na}$ and $\mathrm{Ca}$. Again, this mirrors the patterns seen in IC/IC-PMS data, where the primary source of both $\mathrm{Ca}$ and $\mathrm{Na}$ at South Pole has been shown to be seasalt aerosols (Tuncel and others, 1989; Legrand and Mayewski, 1997). The predominance of marine aerosols at South Pole is a result of close proximity to their source, whereas crustal materials are transported from temperate latitudes in the middle to upper troposphere (Tuncel and others, 1989). As a result of the decreased transit time, marine aerosols are less extensively scavenged from the atmosphere and appear more predominantly in the ice sheet (Shaw, 1979).

Although increases in continental/dust material are seen at South Pole during the austral summer, owing to the weakened temperature inversion over the polar ice cap and weakened cyclonic wind system around Antarctica, the marine source still overshadows the continental/dust input (Legrand and Mayewski, 1997). Such seasonal trends are also seen when the average frequency of occurrence of each of the eight most common elements during summer and winter is calculated (Fig. 6). During winter, Na occurs more frequently in the impurity particles, whereas dust species are more prevalent during summer. The findings from EDS analysis and from IC/IC-PMS analysis of other cores in the same region record similar trends. This shows that differences in air-mass sources and patterns of site-specific chemistry can be accurately determined using EDS analysis.

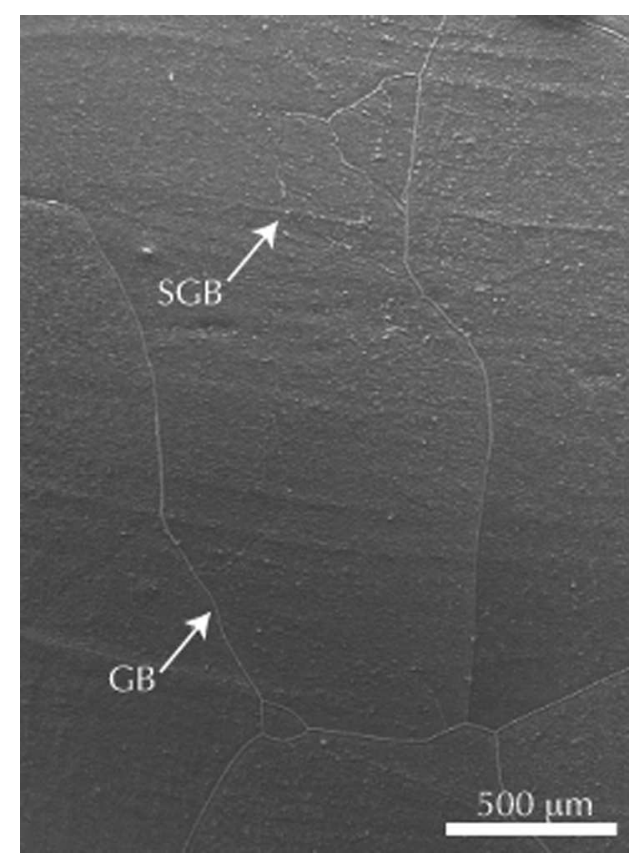

Fig. 9. Subgrain boundaries in a sample from $\sim 50 \mathrm{~m}$ at core site 07-1. They appear faint and kinked, whereas grain boundaries are thicker and straighter.

\section{Trends in loading}

In Antarctic ice cores, the vast majority of $S$ is in the form of $\mathrm{SO}_{4}{ }^{2-}$ (personal communication from S.B. Sneed, 2008. This chemical configuration allows the patterns in $\mathrm{IC} \mathrm{SO}_{4}{ }^{2-}$ chemistry discussed above to be compared to the patterns in $S$ chemistry as derived from EDS. In core 06-1, S loads only on F3, which accounts for $15.1 \%$ of the variability, indicating that $\mathrm{SO}_{4}{ }^{2-}$ is not a major contributor to total aerosol loading at site $06-1 . \mathrm{K}$ and $\mathrm{Cl}$ also load on F3 (Table $3 \mathrm{~A}$ ), indicating that the little $\mathrm{SO}_{4}{ }^{2-}$ present is marinesourced. This is in keeping with trends determined using traditional methods which show that at Taylor Dome, $\mathrm{SO}_{4}{ }^{2-}$ is primarily related to marine biogenic sources, with terrestrial biogenic and volcanic sources being less dominant (Steig and others, 2000).

In core $07-4$, $S$ loads on $F 1$, accounting for $45.6 \%$ of the variability. $F 1$ also includes negative factor loadings for $\mathrm{Al}$ and Si (Table 3D). S, Si and Al load on the same factor in core 06-2 (Table 3B). However, in 06-2, all elements present on $F 1$ have positive factor loadings indicating a shared source (possibly cyclonic systems crossing the Ross Ice Shelf (Steig and others, 2000)), whereas in core 07-4 the loadings for $\mathrm{Al}, \mathrm{Si}$ and $\mathrm{S}$ are opposite in sign as compared to other elements loading on that factor indicating a different source (likely crustal materials and volcanic emissions from the mid-latitudes). Budner and Cole-Dai (2003) showed that South Pole ice cores record volcanic mass aerosol loading from all sources with greater fidelity than other ice cores from East Antarctica, indicating that the $\mathrm{SO}_{4}{ }^{2-}$ record at South Pole should exhibit a greater contribution from volcanic aerosols than other sites, as it does in 07-4. Additionally, $\mathrm{SO}_{4}{ }^{2-}$ is the dominant aerosol species in the summer at South Pole as a result of the strength of the Ross Sea/lce Shelf low-pressure system (Arimoto and others, 2004) and therefore should contribute more to total aerosol loading, as it does in 07-4. The results of the factor analysis indicate that variations in the sulfate loading and source, as 


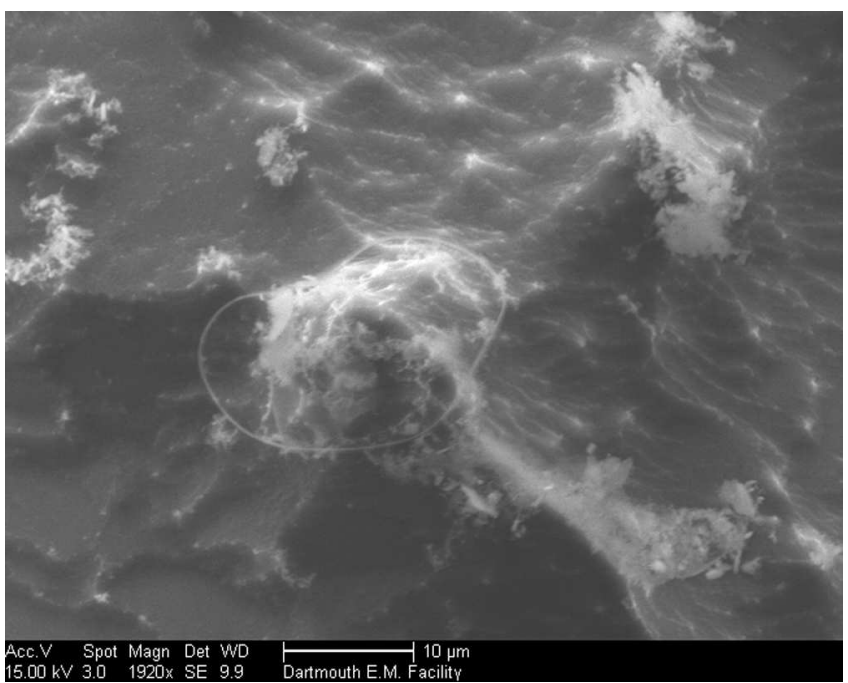

Fig. 10. Filament around soluble impurity at facet peak from $07-4$ at $11.3 \mathrm{~m}$.

suggested by other techniques, (i.e. potentially increased volcanic $\mathrm{SO}_{4}{ }^{2-}$ loading in core 07-4 compared to core 06-1) can also be determined by EDS impurity analysis.

\section{Overall trends}

The results of the factor analysis described above indicate that EDS analysis of impurities can provide valuable data regarding the elemental chemistry of ice-core samples, including variations in air-mass trajectories. The differences in factor loadings between 06-1, 06-2 and 06-3, all of which have relatively coastal locations and are in close proximity, may reflect changes in the seasonality or storm trajectories of layers sampled. Additionally, they may give some indication of the importance of site-scale effects (micrometeorology, surface topography, etc.) on deposition and subsequent incorporation into the ice sheet.

Because these determinations can be made at high resolution (sub-centimeter) it may be possible, using the techniques described here and a more focused characterization of soluble and particulate impurities, to accurately compare the chemistry of continuous stratigraphic layers, as traced with GPR, in cores from distal locations. These applications would contribute greatly to the understanding of the spatial and temporal changes in environmental conditions throughout Antarctica.

\section{Morphology and microstructural location of impurities}

The elements or combination of elements present indicate, at least in part, the morphology and microstructural location of impurities in glacial firn/ice. The positive association found between filaments (FIL) and sea-salt species in three of the four cores indicates that filament formation requires the presence of salts (Table 3B-D), which has been observed previously in filaments in snow, firn and ice (Cullen and Baker, 2001; Obbard and others, 2003; Barnes and Wolff, 2004; Rosenthal and others, 2007; Iliescu and Baker, 2008). The formation of filaments is believed to result from the concentration of impurities via localized surface diffusion of impurities as the surrounding ice is sublimated. Filaments are often found in grain boundaries, as they are areas of high free energy and sublimate the most rapidly (Cullen and
Baker, 2001; Baker and Cullen, 2003). The analyzed grain boundaries (GB) that did not contain filaments were typically inversely related to all elements, perhaps indicating that the concentration necessary to form filaments had not yet been attained.

Extended sublimation (5-8 months) results in the formation of filaments on the bulk of the ice as well (Rosenthal and others, 2007). Although the samples in this study did not sublimate for an extended period, an intragranular filament was found encircling impurities collected at the peak of a crystal facet (Fig. 10). Similar to grain boundaries, the surface energy at both a facet peak and around an impurity would be greater than in the surrounding ice. The presence of this intragranular filament may indicate that filaments will form wherever the concentration of impurities (resulting from localized surface diffusion) is above a threshold value. This supports the theory that filaments are formed during sublimation and are not frozen ice veins (Baker and Cullen, 2003).

While the formation of filaments requires the presence of salts, the formation of filament tufts or tangles (TAN) is positively associated with the presence of dust species (AI, $\mathrm{Si}$; Table 3). One possible explanation for this association is that the tuft or tangle-like morphology is only possible if there is a dust particulate nucleus for the filament (formed from salt) to tangle around. Cullen (2002) showed SEM images of a diamond-shaped inclusion (consisting of $\mathrm{Mg}$ and S) both before and after a nearby filament (also consisting of $\mathrm{Mg}$ and S) became wrapped around it. Although no such progression was captured in the study described in this paper, it provides a likely analog. Cullen (2002) also reported that the grain boundary filaments in the Byrd core versus those in the GISP2 (Greenland Ice Sheet Project 2) core were compositionally different, containing primarily $\mathrm{Mg}$ and $\mathrm{S}$ versus $\mathrm{Na}$ and $\mathrm{Cl}$, respectively. Both cores had similar physical appearance, soluble lattice (intragranular) chemistry, and soluble impurity levels as determined by IC, so Cullen (2002) attributed the differences in filament chemistry to either the presence of nonionic dust species (e.g. $\mathrm{Al}$ and $\mathrm{Si}$ ) or to unknown environmental differences at the core sites. Filaments (FIL) observed in this study unilaterally contained $\mathrm{Cl}$, while filament tufts unilaterally contained Si, but also commonly contained $\mathrm{Cl}$. These chemical characterizations in conjunction with Cullen's (2002) photographs indicate that filaments on the sublimating surface may be drawn towards nearby particulates, thereby forming filament tufts.

Bright white spots (BWS) are the most prevalent impurity type, and previous research has shown that the BWS in a sample allowed to sublimate for a greater length of time becomes both larger and more numerous in accordance with the theory of concentration via localized surface diffusion (Cullen and Baker, 2001). An association between BSW and any particular element or combination of elements was not observed in this study (Table 3). This lack of association may be due to incorrect categorization as a result of the limited sublimation time in the SEM chamber. It is possible that some impurities placed in this category were insoluble particulates (INC) that had not been fully exposed by sublimation, and thus only appeared as bright white spots (BWS). Both dust elements (Al, Si) and marine components $(\mathrm{Cl}, \mathrm{S})$ have been reported in bright white spots (Cullen and Baker, 2001; Barnes and others, 2002a,b; Baker and Cullen, 2003; Obbard and others, 2003; Baker and others, 2005). Rempel and others (2001) found that dust particles might be coated with a 
Table 4. Factor analysis of elemental variables in cores 07-4 (EDS) and 03-1 and 02-5 (IC-PMS). Factor loadings greater than 0.7 are italicized

\begin{tabular}{|c|c|c|c|c|c|c|c|c|}
\hline & $F 1$ & $F 2$ & & $F 1$ & $F 2$ & & $F 1$ & $F 2$ \\
\hline Core 07-4 & & & Core 02-5 & & & Core 03-1 & & \\
\hline $\mathrm{Al}$ & -0.44 & -0.68 & $\mathrm{Al}$ & -0.72 & - & $\mathrm{Al}$ & 0.87 & - \\
\hline $\mathrm{Ca}$ & - & 0.82 & $\mathrm{Ca}$ & - & -0.74 & $\mathrm{Ca}$ & - & - \\
\hline $\mathrm{Cl}^{-}$ & - & 0.72 & $\mathrm{Cl}^{-}$ & 0.92 & - & $\mathrm{Cl}^{-}$ & -0.46 & -0.64 \\
\hline $\mathrm{Mg}$ & 0.89 & - & Mg & - & - & Mg & - & - \\
\hline $\mathrm{Na}$ & - & - & $\mathrm{Na}$ & 0.95 & - & $\mathrm{Na}$ & -0.77 & - \\
\hline S & 0.97 & - & $\mathrm{S}$ & -0.59 & 0.82 & $S$ & - & 1.00 \\
\hline$\%$ of variance & 32.60 & 28.08 & $\%$ of variance & 46.98 & 22.90 & $\%$ of variance & 28.74 & 26.32 \\
\hline
\end{tabular}

liquid film in association with interfacial pre-melting. If the dust particles are associated with soluble impurities, this phenomenon could also explain the lack of association between BWS and any particular set of elements.

Triple junctions (TJ) have a negative association with continental/dust species (Ca, Al, Si) in two cores (Table 3A and $\mathrm{B}$ ) and are negatively associated with $\mathrm{Ca}$ and $\mathrm{S}$ in a third (Table 3C). One possible explanation for this negative relationship is that dust particles may not move into triple junctions. However, previous research has shown that soluble impurities within ice grains will be swept into grain boundaries as they migrate, particularly during recrystallization (Glen and others, 1977; Iliescu and Baker, 2008). A shear strain of $\sim 1.15$ was applied to the samples used by Iliescu and Baker (2008), whereas the samples used in this study were collected from a shallow part of the ice sheet and have very little accumulated strain history. The straininduced grain boundary migration in Iliescu and Baker (2008) is therefore unlikely to be consistent with the strain experienced by the samples used in this study. The lack of accumulated strain history in this study's samples means less, if any, grain boundary migration and therefore fewer continental/dust impurities swept into the boundaries. These differences in strain history may explain why dust species were negatively associated with triple junctions in this study, whereas previous studies (Iliescu and Baker, 2008) suggest a positive correlation.

Very few triple junctions (TJ) were analyzed in core 07-4, so no association with any elemental species could be determined. However, evidence of the influence of dust species on grain size was found by other means. The impurities analyzed in core 07-4 had the lowest concentrations of continental/dust species, but their sampling frequency (i.e. $\mathrm{Si}$ and $\mathrm{Al}$; Fig. 6) was higher than in any other core. Core 07-4 has the smallest overall grain size, given the high continental/dust sampling frequency; it is possible that decreased grain size is a result of increased dust loading. Dust content and porosity are positively related, while grain size and porosity are negatively related, indicating that in these cores, grain size is partially controlled by dust content. However, there are also several alternate explanations for the decreased grain size at site 074 , including mean annual temperature, so the relationship between grain size and dust content may be from one or a combination of factors.

There were no clear patterns of association between any elements or combination of elements and large inclusions (INC). In core 06-1, the association of INC and FIL (which requires salts), along with the association of marine-sourced
$\mathrm{K}$, may indicate that INC formation requires marine species. However, very few impurities were identified as INC, and some INC may have been identified as BWS as discussed above, possibly explaining the lack of any clear pattern of association between the characteristics examined and this impurity type.

\section{Comparison with other methodologies}

The microstructural characterization of impurities may aid in the interpretation of IC and ICPMS data, so it is important to understand the relationships between the types of measurements. Previous research (Cullen, 2002) showed that despite having similar chemistry, as measured by IC, the Byrd and GISP2 cores had very different filament chemistry as determined using EDS. As discussed earlier, these differences may be attributable to the presence of nonionic (insoluble) particulates. IC-PMS has not yet been completed on the cores used in this study; however, data from two cores located to the east (03-1) and west (02-5) (personal communication from D. Dixon, 2008) of core 07-4 (Fig. 1) are compared.

Factor analysis of the concentrations of elements found using both EDS and IC-PMS in the three South Polar cores $\left(\mathrm{Na}, \mathrm{Ca}, \mathrm{Mg}, \mathrm{Al}, \mathrm{Cl}^{-}\right.$and $\mathrm{S}$ ) revealed site-specific differences in factor loadings (Table 4). (Note that the high ionization potential of $\mathrm{Cl}$ precludes its measurement using IC-PMS, so $\mathrm{Cl}^{-}$values from IC are used instead. Because there are so few particulates in Antarctic ice cores and because $\mathrm{Cl}^{-}$is unlikely to be associated with silicates, which would require acid digestion, the discrepancy between the two measurement types for this ion/element should be minimal.) The differences are assumed to result from dissimilarity in elemental aerosol and particulate loading, rather than from methodology. They are similar in scale to those found for cores 06-1, 06-2 and 06-3 as determined using a single method (EDS). Because cores 07-4, 02-5 and 03-1 are as geographically distant from one another as the 06 cores are, the difference in factor loading can be attributed to either dissimilarities in aerosol/particulate deposition or incorporation into the ice sheet owing to micrometeorological effects, as was the case for the 06 cores.

To further compare the two methodologies, selected ratios $\left(\mathrm{Na} / \mathrm{S}, \mathrm{Ca} / \mathrm{S}, \mathrm{Ca} / \mathrm{Al}, \mathrm{Na} / \mathrm{Ca}, \mathrm{Cl}^{-} / \mathrm{Na}, \mathrm{S} / \mathrm{Cl}^{-}\right)$of several common elements from both analytical techniques were compared. Ratios were used because it is not valid to compare counts from EDS with concentration from IC-PMS. The combination of elements analyzed as ratios was chosen based on the correlation matrices for the three samples. Histograms of the frequency with which each of the 

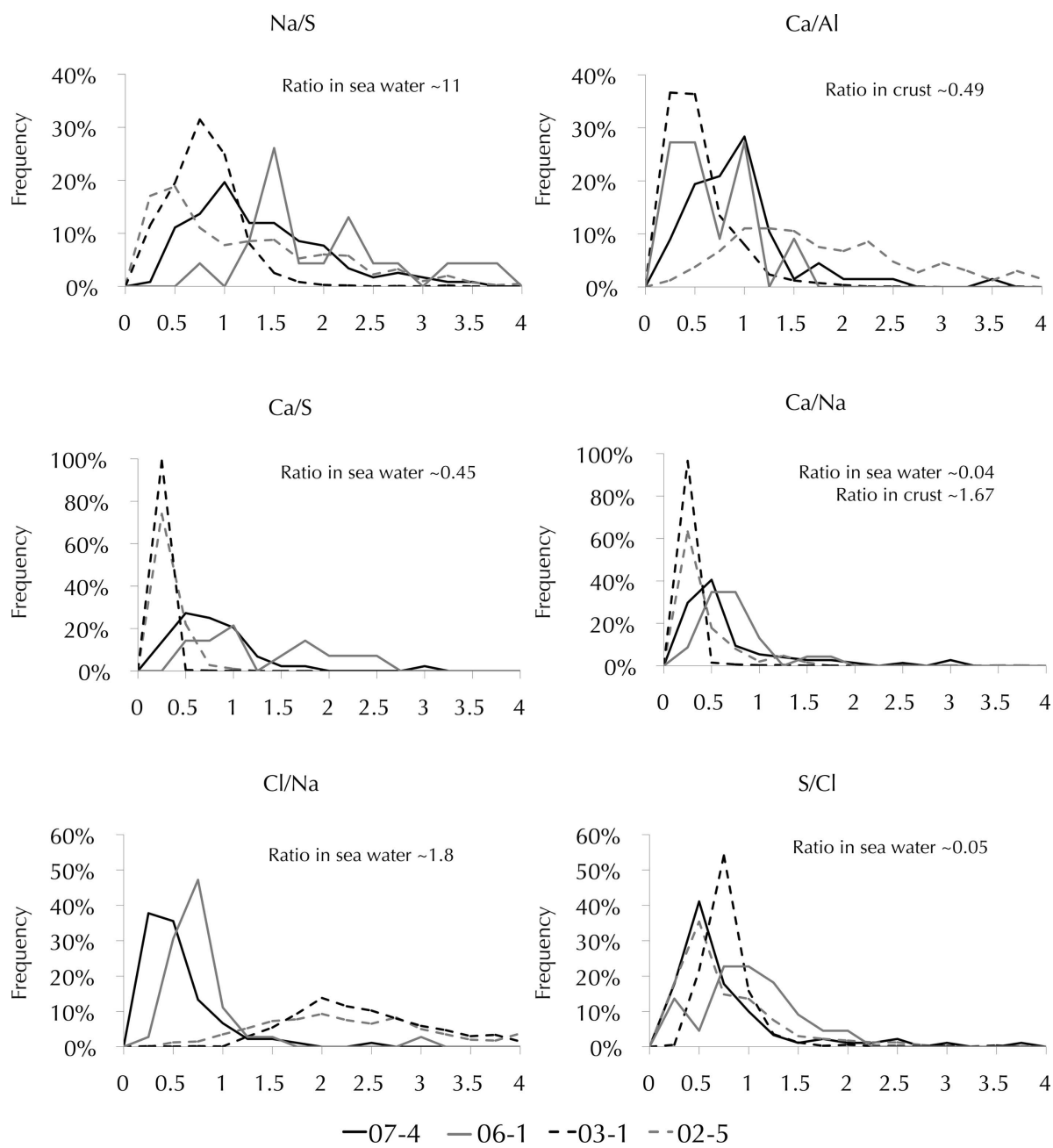

Fig. 11. Histogram of the frequency of occurrence of elemental ratios. Ratios from EDS are shown for cores 07-4 and 06-1. 03-1 and 02-5 were analyzed using IC-PMS. Sea-water and crust ratios from Wilson (1975) and Wedepohl (1995).

elemental ratios occurred in the samples are presented in Figure 11. Data from core 06-1 are included as well, in order to see if the different methodologies produced more similar ratios. Figure 11 shows that the ratios in the two EDS samples are more similar to one another, despite how geographically distant they are, than are the ratios of the EDS South Polar sample (07-4) and the geographically proximal IC-PMS samples (02-5 and 03-1).

The relationships seen in Figure 11 may indicate that the differences between EDS analysis and IC-PMS analysis render the comparison of these data impossible. However, it should be noted that EDS sampling of impurities was very random. A more detailed centimeter-by-centimeter comparison of IC-PMS and EDS chemistry from core 07-4 is being completed in order to better assess the differences between EDS and IC-PMS analysis. These data will also be used to examine the relationship between the physical and chemical characteristics within shallow firn in greater detail.

\section{CONCLUSIONS}

The characterization of physical properties in four cores from the US ITASE traverses of 2006 and 2007 (06-1, 06-2, 06-3 and 07-4) revealed site-specific details that would have been missed if only chemical characterization had been completed. Characterization of internal surface volume, $S_{V}$, at site $07-4$ and others showed that the progression from firn to ice is not entirely linear, as would be assumed if only grain size or porosity were considered. Further investigation of changes in $S_{\mathrm{V}}$ with depth may aid in the understanding of the processes of firn densification and metamorphism in the ice sheet. The findings described above indicate the importance of characterizing multiple parameters to the understanding of ice cores as climate proxies.

The high degree of clustering of poles in sample 06-1-97 and the inclusion of a great number of low-angle misorientations indicate subgrain formation. Subgrains are not typically expected to form in the shallow parts of the ice sheet, but visual evidence of subgrain formation was found in samples as shallow as $50 \mathrm{~m}$. These findings indicate that SEM and EBSD are valuable techniques for investigations of strain in the shallow parts of ice sheets.

The inter-regional trends in aerosol/particulate loading determined by EDS analysis of impurities are in accordance with those previously published from IC and IC-PMS data. The previously established patterns of $\mathrm{Na}$ and $\mathrm{Ca}$ deposition at Taylor Dome where $\mathrm{Ca}$ is primarily continental and $\mathrm{Na}$ is primarily marine (De Angelis and others, 1997; Legrand and Mayewski, 1997; Steig and others, 2000) and South Pole where both are primarily marine (Tuncel and others, 1989; Legrand and Mayewski, 1997) were accurately determined using EDS. The differences in patterns of $\mathrm{SO}_{4}{ }^{2-}$ between the sites also indicate dissimilar $\mathrm{SO}_{4}{ }^{2-}$ sources (i.e. volcanic versus oceanic). In addition to accurately characterizing 
differences in loading and incorporation into the ice sheet, EDS analysis also identified the general trend of decreasing concentration with movement inland.

The morphology and microstructural location of impurities was found to be dependent upon the elements present. As was determined in previous studies (Cullen and Baker, 2001; Obbard and others, 2003; Barnes and Wolff, 2004; Rosenthal and others, 2007; Iliescu and Baker, 2008), the formation of filaments (FIL) was found to require the presence of marine species, whereas bright white spots (BWS) contained both marine and continental species. Not reported elsewhere is the characterization of filament tufts (TAN), which require the presence of continental (dust) species for their formation.

The analysis of both the soluble and insoluble chemistry and physical properties within a single firn or ice specimen suggests that both properties can provide valuable insights regarding environmental conditions at the time of deposition (temperature, atmospheric chemistry, atmospheric circulation patterns, etc.) and conditions affecting post-depositional incorporation into the ice sheet (micrometeorological differences, shallow firn metamorphism, accumulation hiatuses). Many of these properties are intricately linked and investigations of their relationships using SEM, EDS and EBSD will advance our understanding of the spatial and temporal changes in the climate of Antarctica in a way that no other instrumentation or technique could.

\section{ACKNOWLEDGEMENTS}

The US National Science Foundation (NSF) Office of Polar Programs is acknowledged for funding this project under OPP 0538494. Also acknowledged are participants of the 2006 and 2007 US ITASE traverses involved in the collection and preparation of ice cores for this research. C. Daghlian of the Dartmouth Medical School Electron Microscope Facility and S. Sneed of the University of Maine Climate Change Chemistry Laboratory are thanked for lending their time and expertise. A final thanks to reviewers T. Thorsteinsson and $M$. Tranter whose attention to detail and insightful comments greatly improved the quality of the manuscript.

\section{REFERENCES}

Alley, R.B. 1987. Firn densification by grain-boundary sliding: a first model. J. Phys. [Paris], 48, Colloq. C1, 249-254. (Supplément au 3.)

Alley, R.B. 1992. Flow-law hypotheses for ice-sheet modeling. J. Glaciol., 38(129), 245-256.

Alley, R.B. and G.A. Woods. 1996. Impurity influence on normal grain growth in the GISP2 ice core, Greenland. J. Glaciol., 42(141), 255-260.

Alley, R.B., J.H. Perepezko and C.R. Bentley. 1986. Grain growth in polar ice: I. Theory. J. Glaciol., 32(112), 415-424.

Alley, R.B., A.J. Gow, S.J. Johnsen, J. Kipfstuhl, D.A. Meese and T. Thorsteinsson. 1995a. Comparison of deep ice cores. Nature, 373(6513), 393-394.

Alley, R.B., A.J. Gow and D.A. Meese. 1995b. Mapping c-axis fabrics to study physical processes in ice. J. Glaciol., 41(137), 197-203.

Anderson, D.L. and C.S. Benson. 1963. The densification and diagenesis of snow. In Kingery, W.D., ed. Ice and snow: properties, processes, and applications. Cambridge, MA, M.I.T. Press, 391-411.
Arimoto, R. and 7 others. 2004. Major ions and radionuclides in aerosol particles from the South Pole during ISCAT-2000. Atmos. Environ., 38(32), 5473-5484.

Arnaud, L., M. Gay, J.M. Barnola and P. Duval. 1998. Imaging of firn and bubbly ice in coaxial reflected light: a new technique for the characterization of these porous media. J. Glaciol., 44(147), 326-332.

Arnaud, L., J.M. Barnola and P. Duval. 2000. Physical modeling of the densification of snow/firn and ice in the upper part of polar ice sheets. In Hondoh, T., ed. Physics of ice core records. Sapporo, Hokkaido University Press, 285-305.

Baker, I. and D. Cullen. 2003. SEM/EDS observations of impurities in polar ice: artifacts or not? J. Glaciol., 49(165), 184-190.

Baker, I., D. Iliescu, R. Obbard, H. Chang, B. Bostick and C.P. Daghlian. 2005. Microstructural characterization of ice cores. Ann. Glaciol., 42, 441-444.

Baker, I., R. Obbard, D. Iliescu and D. Meese. 2007. Microstructural characterization of firn. Hydrol. Process., 21(12), 1624-1629.

Barnes, P.R.F. and E.W. Wolff. 2004. Distribution of soluble impurities in cold glacial ice. J. Glaciol., 50(170), 311-324.

Barnes, P.R.F., R. Mulvaney, K. Robinson and E.W. Wolff. 2002a. Observations of polar ice from the Holocene and the glacial period using the scanning electron microscope. Ann. Glaciol., 35, 559-566.

Barnes, P.R.F., R. Mulvaney, E.W. Wolff and K. Robinson. 2002b. A technique for the examination of polar ice using the scanning electron microscope. J. Microsc., 205(2), 118-124.

Barnes, P.R.F., E. Wolff, D.C. Mallard and H.M. Mader. 2003. SEM studies of the morphology and chemistry of polar ice. Microsc. Res. Techn., 62(1), 62-69.

Bertler, N.A.N. and 53 others. 2005. Snow chemistry across Antarctica. Ann. Glaciol., 41, 167-179.

Bromwich, D.H. 1988. Snowfall in high southern latitudes. Rev. Geophys., 26(1), 149-168.

Budner, D. and J. Cole-Dai. 2003. The number and magnitude of large explosive volcanic eruptions between 904 and 1865 A.D.: quantative evidence from a new South Pole ice core. In Robock, A. and C. Oppenheimer, eds. Volcanism and the Earth's atmosphere. Washington, DC, American Geophysical Union, 165-176. (Geophysical Monograph 139.)

Cuffey, K.M., T. Thorsteinsson and E.D. Waddington. 2000. A renewed argument for crystal size control of ice sheet strain rates. J. Geophys. Res., 105(B12), 27,889-27,894.

Cullen, D.C. 2002. The structure and chemistry of polar glacier ice. (PhD thesis, Dartmouth College.)

Cullen, D. and I. Baker. 2001. Observation of impurities in ice. Microsc. Res. Techn., 55(3), 198-207.

Davis, J.C. 2002. Statistics and data analysis in geology. Third edition. New York, Wiley.

Day, A.P., P. Trimby, K. Mehnert and B. Neumann. 2004. Channel 5 user manual. Hobro, HKL Technology ApS.

De Angelis, M., J.P. Steffensen, M. Legrand, H. Clausen and C. Hammer. 1997. Primary aerosol (sea salt and soil dust) deposited in Greenland ice during the last climatic cycle: comparison with East Antarctic records. J. Geophys. Res., 102(C12), 26,681-26,698.

Durand, G., A. Perrson, D. Samyn and A. Svensson. 2008. Relation between neighbouring grains in the upper part of the NorthGRIP ice core - implications for rotation recrystallization. Earth Planet. Sci. Lett., 265(3-4), 666-671.

Ebinuma, T. and N. Maeno. 1987. Particle rearrangement and dislocation creep in a snow-densification process. J. Phys. [Paris], 48, Colloq. C1, 263-268. (Supplément au 3.)

Fitch, R.K. 2007. WinSTAT, version 2007.1. Chicago, IL, R. Fitch Software.

Freitag, J., F. Wilhelms and S. Kipfstuhl. 2004. Microstructuredependent densification of polar firn derived from X-ray microtomography. J. Glaciol., 50(169), 243-250.

Glen, J.W., D.R. Homer and J.G. Paren. 1977. Water at grain boundaries: its role in the purification of temperate glacier ice. 
IAHS Publ. 118 (Symposium at Grenoble 1975 - Isotopes and Impurities in Snow and Ice), 263-271.

Goldstein, J. and 7 others. 1992. Scanning electron microscopy and $X$-ray microanalysis. Second edition. New York, Plenum Press.

Gow, A.J. 1969. On the rates of growth of grains and crystals in South Polar firn. J. Glaciol., 8(53), 241-252.

Hamann, I., S. Kipfstuhl, S.H. Faria, A. Lambrecht, D. Grigoriev and F. Marino. 2004. Grain boundary hierarchy in the EPICADML deep ice core, Antarctica. Geophys. Res. Abstr., 6, EGU04A-06791.

Hooke, R.LeB. and P.J. Hudleston. 1980. Ice fabrics in a vertical flow plane, Barnes Ice Cap, Canada. J. Glaciol., 25(92), 195-214.

Iliescu, D. and I. Baker. 2008. Effects of impurities and their redistribution during recrystallization of ice crystals. J. Glaciol., 54(185), 362-370.

Kaiser, H.F. 1960. The application of electronic computers to factor analysis. Educ. Psychol. Meas., 20(1), 141-151.

Kamb, W.B. 1959. Ice petrofabric observations from Blue Glacier, Washington, in relation to theory and experiment. J. Geophys. Res., 64(11), 1891-1909.

Kipfstuhl, S. and 6 others. 2006. Microstructure mapping: a new method for imaging deformation-induced microstructural features of ice on the grain scale. J. Glaciol., 52(178), 398-406.

Kreutz, K.J., P.A. Mayewski, S.I. Whitlow and M.S. Twickler. 1998. Limited migration of soluble ionic species in a Siple Dome, Antarctica, ice core. Ann. Glaciol., 27, 371-377.

Legrand, M. and P. Mayewski. 1997. Glaciochemistry of polar ice cores: a review. Rev. Geophys., 35(3), 219-243.

Maeno, N. and T. Ebinuma. 1983. Pressure sintering of ice and its implication to the densification of snow at polar glaciers and ice sheets. J. Phys. Chem., 87(21), 4103-4110.

Mardia, K.V., J.T. Kent and J.M. Bibbly. 1979. Multivariate analysis (probability and mathematical statistics). San Diego, CA, Academic Press.

Mayewski, P.A. 1996. US ITASE: science and implemenation plan. Durham, NH, University of New Hampshire.

Mayewski, P.A. and 18 others. 2006. The International TransAntarctic Scientific Expedition (ITASE): an overview. Ann. Glaciol., 41, 180-185.

Mil-Homens, M. and 6 others. 2009. Using factor analysis to characterise historical trends of trace metal contamination in a sediment core from the Tagus Prodelta, Portugal. Water, Air, Soil Pollut., 197(1-4), 277-287.

Obbard, R. and I. Baker. 2007. The microstructure of meteoric ice from Vostok, Antarctica. J. Glaciol., 53(180), 41-62.

Obbard, R., D. Iliescu, D. Cullen and I. Baker. 2003. SEM/EDS comparison of polar and seasonal temperate ice. Microsc. Res. Techn., 62(1), 49-61.

Obbard, R., I. Baker and D. Iliescu. 2006. Correspondence. Grain boundary grooving in ice in a scanning electron microscope. J. Glaciol., 52(176), 169-172.
Rempel, A.W., J.S. Wettlaufer and M.G. Worster. 2001. Interfacial premelting and the thermomolecular force: thermodynamic buoyancy. Phys. Rev. Lett., 87(8), 088501. (10.1103/ PhysRevLett.87.088501.)

Rosenthal, W., J. Saleta and J. Dozier. 2007. Scanning electron microscopy of impurity structures in snow. Cold Reg. Sci. Technol., 47(1-2), 80-89.

Shaw, G.E. 1979. Consideration on the origin and optical properties of the Antarctic aerosol. Rev. Geophys. Space Sci., 17(8), 1983-1998.

Spaulding, N.E., D.A. Meese, I. Baker, P.A. Mayewski and G.S. Hamilton. 2010. A new technique for firn grain-size measurement using SEM image analysis. J. Glaciol., 56(195), $12-19$.

Steig, E.J. and 7 others. 2000. Wisconsinan and Holocene climate history from an ice core at Taylor Dome, western Ross Embayment, Antarctica. Geogr. Ann., 82A(2-3), 213-235.

Steig, E.J. and 16 others. 2005. High-resolution ice cores from US ITASE (West Antarctica): development and validation of chronologies and determination of precision and accuracy. Ann. Glaciol., 41, 77-84.

Stephenson, P.J. 1967. Some considerations of snow metamorphism in the Antarctic ice sheet in the light of ice crystal studies. In Oura, H., ed. Physics of snow and ice. Sapporo, Hokkaido University. Institute of Low Temperature Science, 725-740.

Thompson, L.G. and E. Mosley-Thompson. 1982. Spatial distribution of microparticles with Antarctic snow-fall. Ann. Glaciol., 3, 300-306.

Thorsteinsson, T. 2002. Fabric development with nearest-neighbour interaction and dynamic recrystallization. J. Geophys. Res., 107(B1), 2014. (10.1019/2001JB000244.)

Thorsteinsson, T., J. Kipfstuhl, H. Eicken, S.J. Johnsen and K. Fuhrer. 1995. Crystal size variations in Eemian-age ice from the GRIP ice core, central Greenland. Earth Planet. Sci. Lett., 131(3-4), 381-394.

Tuncel, G., N.K. Aras and W.H. Zoller. 1989. Temporal variations and sources of elements in the South Pole atmosphere. 1. Nonenriched and moderately enriched elements. J. Geophys. Res., 94(D10), 13,025-13,038.

Wedepohl, K.H. 1995. The composition of the continental crust. Geochim. Cosmochim. Acta, 59(7), 1217-1232.

Wilkinson, D.S. 1988. A pressure-sintering model for the densification of polar firn and glacier ice. J. Glaciol., 34(116), 40-45.

Wilson, T.R.S. 1975. Salinity and the major elements of sea water. In Riley, J.P. and G. Skirrow, eds. Chemical oceanography, Vol. 1. London, Academic Press, 365-413.

Zwally, H.J. and M.B. Giovinetto. 1997. Annual sea level variability induced by changes in sea ice extent and accumulation on ice sheets: an assessment based on remotely sensed data. In Plag, H.-P. and S. Klosko, eds. Geophysical evidence of past and present climate change. Dordrecht, etc., Kluwer Academic Publishers, 327-340. (Surveys in Geophysics 18.) 